\title{
Approaches to Copyright Education for Faculty in Canada
}

Jennifer Zerkee, MAS

Copyright Specialist

Simon Fraser University

istevens@sfu.ca

\section{Abstract}

This study surveyed copyright administrators at Canadian universities about their methods of providing copyright training to faculty and non-faculty instructors, the frequency and topics of education provided, and the modes of communication used to reach instructors. Copyright administrators were also asked to rate the perceived effectiveness of their educational opportunities.

Respondents feel that in-person education is most effective for providing copyright training to instructors, though a significant number of respondents do not believe that all instructors at their institutions are made adequately aware of copyright educational opportunities. Lack of time and staffing resources affect many copyright administrators. These challenges are leading many to develop more systematic approaches to reaching instructors. Communication and education are being provided directly to individual departments and by working with administrators and others at the department level.

Considering the siloed nature of many copyright offices and positions, this study aims to share the approaches being taken by copyright administrators to educate instructors about their rights and responsibilities with regard to copyright and teaching.

\section{Introduction}

Academic libraries and librarians are often the go-to source for copyright information on college and university campuses (Albitz, 2013, p. 431-432). In recent years this role has become more formalized with the establishment of copyright offices and the increasing number of librarian positions addressing copyright, such as copyright officers, copyright librarians, and scholarly communication librarians (Patterson, 2016, p. 3-4; Graham \& Winter, 2016; Kawooya, Veverka, \& Lipinski, 2015). Librarians have also taken on an increasing instructional role in relation to information literacy (see for example Julien, Tan, \& Merillat, 2013, p. 82; and Cox \& Corrall, 2013, p. 1534), of which copyright forms a part, and thus education is often a central focus of these new copyright offices and positions.

At many Canadian institutions this increased formalization of academic libraries' focus on copyright was necessitated by a move away from agreements with collective 
licensing organizations Access Copyright and Copibec, and toward managing copyright compliance internally (Graham \& Winter, 2016, p. 15; Katz, 2013). This shift has been guided by judicial rulings emphasizing the balance between users' rights and those of the rights holder and encouraging a "large and liberal" (CCH Canadian Ltd. v Law Society of Upper Canada, para. 51) interpretation of fair dealing purposes. These rulings included CCH Canadian Ltd. v Law Society of Upper Canada (CCH), and the 2012 "pentalogy," which Katz (2013) concluded "with respect to the use of copyrighted materials in the educational and library context,... firmly entrenched [users' rights] as core principles in Canadian copyright law" (p. 213).

As more institutions move away from collective licensing schemes, embrace fair dealing and other exceptions outlined in the Copyright Act, and consider users' rights as defined in the pentalogy cases, it is vital that copyright administrators develop educational programs regarding the use of copyright-protected materials in teaching, research, work, and learning. Education in this new copyright regime should empower instructors to confidently use copyright-protected materials in a way that respects the balance between users' rights and those of the rights holder.

However, educating faculty can be difficult for numerous reasons. Merely reaching faculty, who are spread across departments, have numerous different employment statuses, and work fairly autonomously, can require the use of multiple channels. Quartey (2007) described the challenge of marketing copyright education, "a service that most people did not want to admit they needed" (p. 96); but arguably this is also a service many do not know they need. Copyright can be an invisible issue as it is not always clear when it has been infringed, and infringement or improper use of copyrightprotected material will not prevent an instructor from teaching. Copyright "rules" (including legislation, case law, and guidelines or best practices) have changed frequently and drastically in Canada in recent years (Geist, 2013, p. iii), and instructors may not realize that they may need to change the ways they use copyright-protected materials in their teaching.

Di Valentino (2015) found that $40 \%$ of surveyed Canadian teaching faculty did not know if their institution offered copyright training (p. 6). In light of this finding, combined with this researcher's belief that faculty at her own institution were not being adequately reached with copyright information and educational opportunities, this study aims to capture the current trends in Canadian universities with regard to copyright education for instructors by addressing the following questions:

\footnotetext{
${ }^{1}$ The "copyright pentalogy" (Geist, 2013) of cases in 2012 included Society of Composers, Authors and Music Publishers of Canada v Bell Canada, 2012 SCC 36, [2012] 2 SCR 326 (Bell); Entertainment Software Association v Society of Composers, Authors and Music Publishers of Canada, 2012 SCC 34, [2012] 2 SCR 231 (ESA); Alberta (Education) v Canadian Copyright Licensing Agency (Access Copyright), 2012 SCC 37, [2012] 2 SCR 345 (Alberta (Education)); Rogers Communications Inc. v Society of Composers, Authors and Music Publishers of Canada, 2012 SCC 35, [2012] 2 SCR 283 (Rogers); and Re:Sound v Motion Picture Theatre Associations of Canada, 2012 SCC 28, [2012] 2 SCR 376 (Re:Sound).
} 
- How are copyright officers, copyright librarians, and other copyright administrators reaching instructors with information about copyright and how it affects their teaching?

- What are the most common methods of educating instructors, and how are these opportunities communicated?

- How effective do copyright educators feel their instructional methods are at giving instructors the information they need to find, use, and create teaching materials responsibly with respect to copyright law?

This study also aims to address the small size and siloed nature of many copyright offices and individual copyright librarians by contributing to the sharing of successful copyright education programs. Finally, this study responds to Horava's (2010) call for "opportunities for sharing best practices and experiences to learn from each other's approaches and strategies" (p. 29).

\section{Literature Review}

Numerous authors have considered the academic library's suitability as the centre for copyright knowledge and education on campus. Bay (2001) argued that librarians have a professional responsibility to educate their communities about the "legal and ethical implications" of copyright, but they were "not doing enough" on this front (para. 1). Bay saw libraries as the point of contact between rights holders aggressively protecting their rights in the digital age, and users who may, knowingly or unknowingly, abuse those rights (Bay, 2001, para. 1; see also Bishop, 2011). Di Valentino (2015) found that more than half of surveyed Canadian teaching faculty turn to librarians when they have questions about copyright (p. 6).

The Association of Research Libraries (ARL) created a set of outreach and messaging resources to help academic librarians in the United States educate faculty, students, and administration, feeling that "it would, in fact, be very strange if librarians weren't extremely interested and well-versed in copyright law" since libraries encounter copyright on many fronts (ARL, n.d., "Librarians: Copyright Education in Libraries"). Similarly, in Canada, the Canadian Association of Research Libraries (CARL) compiled "Key Copyright Concepts" for librarians (n.d.). However, Charbonneau and Priehs (2014) found that while most academic librarians do encounter copyright-related questions in their work, only half feel prepared to provide answers and copyright information to patrons (p. 228; see also Schmidt \& English, 2015, p. 739), and many would like additional copyright training themselves (Charbonneau \& Priehs, 2014, p. 230).

A number of researchers have investigated what faculty do and do not know about copyright. In Renner's (2005) study, "most educators indicated that they were unaware or [did] not seem to know where and how to access [copyright policy and management] information" (p. 105). Renner argued for resources and training for faculty in order to "achieve a comprehensive knowledge base of legal information among educators" (2005, p. 105). Sims (2011) also found "considerable weaknesses and gaps" in the 
knowledge level of instructors as well as librarians (p. 282) and provided suggestions for combating these shortcomings by addressing common myths and misconceptions in copyright education.

Others have described the establishment of departments or groups to undertake copyright education. Quartey (2007) described the establishment of the copyright office at Brigham Young University, and Duncan, Clement, and Rozum (2013) described the development of the Utah State University Copyright Committee and its outreach programs. Graveline (2011) provided general advice for libraries wanting to establish a copyright education program, noting the importance of having support from the administration (p. 96) and providing tips for developing effective copyright workshops. In Canada, the University of Toronto Scholarly Communications and Copyright Office has undertaken a number of education and outreach projects, such as the "Open Access Week Alternate Reality Game" (University of Toronto Libraries, 2015) and the Fair Dealing Canada website (http://www.fairdealingcanada.com/), and shared these experiences with colleagues at conferences and online.

Horava's (2010) study aimed to illustrate the copyright environment in Canadian academic institutions and focused on the library as an institution's source of copyright information. Horava also looked at communication of copyright information to patrons, including instructors as well as students, finding that "individual assistance was seen as the most important method (whether included in a formal service or not), as copyright is a notoriously complex subject that requires personalized attention" (p.22). Horava's study resulted in a number of recommendations for academic libraries with regard to copyright awareness, education, and compliance. Key to this study is his call for libraries to "find opportunities for sharing best practices and experiences to learn from each other's approaches and strategies" (p.29).

Di Valentino (2015) responded to Horava with a survey of Canadian teaching faculty, who were asked about the availability of copyright information and training at their institutions. They were also asked to address a series of "real life" questions intended to gauge how they would respond to common teaching scenarios regarding the use of copyright-protected works and where they would turn for support if needed. While the majority of respondents were aware of their institution's copyright policies or guidelines, many did not know if copyright training was available (p. 6).

\section{Methodology}

Ethics approval for this study was received from the Simon Fraser University Office of Research Ethics. Copyright contacts or heads of libraries for the 63 English-speaking and bilingual Universities Canada member institutions with such contact information available on their websites were emailed an invitation to participate with a link to the survey in early March 2016 (see Appendix A for survey questionnaire). All questions were optional. The survey remained open for three weeks; a reminder email was sent after about ten days. 
Thirty-two responses were received for a $50.8 \%$ response rate. Two branch points could lead respondents to early exits from the survey. Early in the survey, answering "No" or "I don't know" to the question "Does your institution have an office or position dedicated to copyright administration?" led four respondents (12.5\%) to exit the survey. About halfway through the survey, answering "No" to the question "Do you or does your office provide copyright education or training (e.g., workshops, online tutorials, drop-in sessions)?" led five more respondents (17.9\%) to exit. Two respondents stopped answering questions part way through, without exiting at a branch point. The majority of the remaining 21 respondents answered nearly every question.

Respondents were asked if they could be contacted with additional questions in a follow-up survey; 17 consented. These respondents were contacted four months after the initial survey and the 14 still interested in participating further were asked three to six additional questions, 13 by email and one in a telephone conversation. Some questions were asked of all respondents, while some questions asked for further elaboration on an individual respondent's comments in the first survey (see Appendix B for sample follow-up questions). Thirteen individuals submitted responses to the followup questions.

\section{Findings}

\section{Demographics}

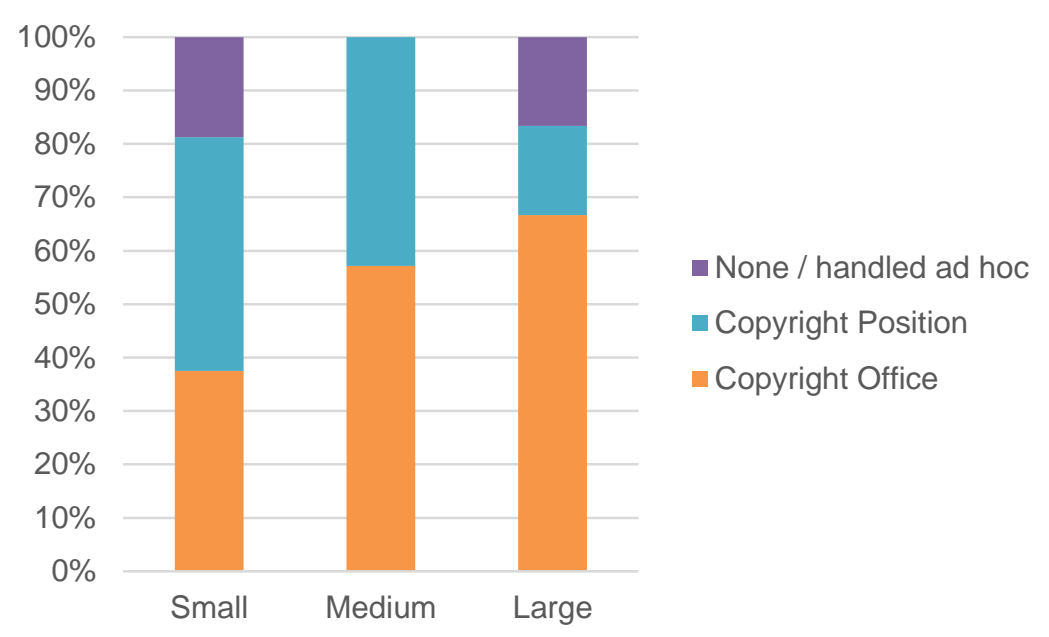

Figure 1. Responsibility for copyright by institution size $(\mathrm{n}=29){ }^{2}$

Half of the responding institutions (50.0\%) have a copyright office or equivalent, while more than one-third (37.5\%) do not have a dedicated copyright office but do have one or more positions that are expressly responsible for copyright, such as a copyright specialist or scholarly communications librarian. The larger the institution, the more

\footnotetext{
2 " $n$ " numbers throughout refer to the total number of responses received for each question.
} 
likely it is to have a copyright office (see Figure 1 ). ${ }^{3}$ The remaining $12.5 \%$ do not have any centralized responsibility for copyright administration and handle copyright issues in an "ad hoc" manner instead; these four respondents all branched to an early exit from the survey.

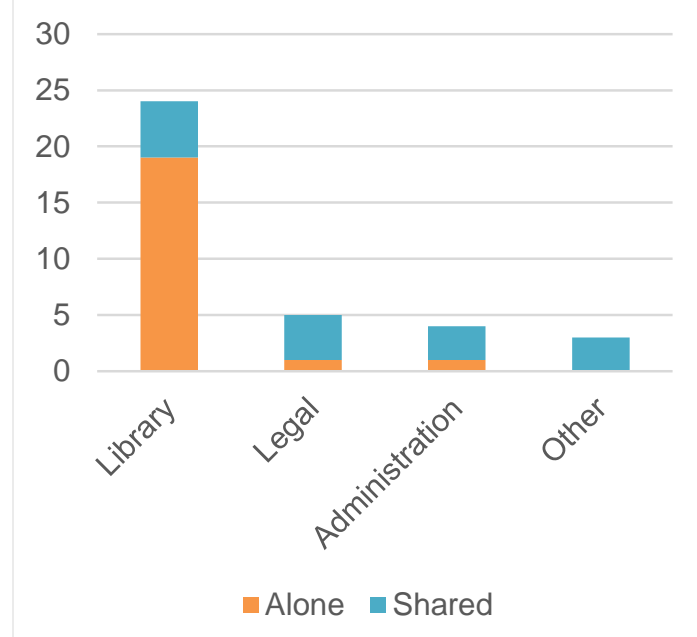

Figure 2. Is your copyright office or position organizationally situated in... ( $n=27)$.

The majority of copyright offices and positions are situated in their institution's library $(70.4 \%)$, followed by a legal office (3.7\%) and institution administration (3.7\%) (see Figure 2). Six respondents (22.2\%) indicated shared responsibility between multiple departments, with most including one or more of these three locations; this brings the number of copyright offices and positions at least partially overseen by the library to $88.9 \%$.

\begin{tabular}{|l|l|}
\hline Table 1 \\
How many years has your copyright office/position been in \\
operation? $(\mathrm{n}=25)$
\end{tabular}

\footnotetext{
${ }^{3}$ Universities Canada's (2015) enrolment data was used to determine the approximate size of each institution (in the 29 cases where respondents indicated the institution's name). Total FTE was estimated by using a $1 / 3$ method (PT x 0.33 ) for part-time students. Institutions were grouped by size based on Horava's (2010) model, where 0-10,000 FTE are "small," 10,001-25,000 "medium," and over 25,000 "large." Findings closely aligned with Horava's (as well as Graham \& Winter's (2016)), with $55.2 \%$ of respondents in the small category, $24.5 \%$ medium, and $20.7 \%$ large. These findings also closely mirrored the makeup of the larger pool of 63 institutions contacted for the survey (57.1\% small, $22.2 \%$ medium, and $20.6 \%$ large).
} 


\begin{tabular}{|l|l|}
\hline Table 2 \\
$\begin{array}{l}\text { How many staff does your copyright office employ, OR } \\
\text { how many staff have copyright-related duties? }(\mathrm{n}=25)\end{array}$ \\
\hline Number of staff & Responses \\
\hline 1 to 2 & 15 \\
\hline 3 to 5 & 7 \\
\hline 6 to 10 & 2 \\
\hline 11 to 20 & 1 \\
\hline
\end{tabular}

Most of the responding copyright offices and positions are relatively new, with a mean age of 7.5 years and a median of 5 years (see Table 1). ${ }^{4}$ This is consistent with the fact that universities began to opt out of a license agreement with Access Copyright and began to manage copyright internally in 2012, after Access Copyright filed an application to drastically increase the Post-Secondary Educational Institutions Tariff (University of British Columbia, 2011; University of Northern British Columbia, 2011; MacPherson, 2012). Most responding offices and positions are also quite small, with $60.0 \%$ consisting of only one or two staff members (see Table 2 ). ${ }^{5}$ Only one respondent $(4.0 \%)$ indicated having more than ten staff, consisting of ten in the library and five in other locations across campus.

Five responding institutions (20.0\%) at the time of the survey had agreements with licensing organizations Access Copyright or Copibec. All five have copyright offices or positions that have been in operation for ten years or less. Though this is a very small sample to extrapolate from, these collective licensing agreements do not seem to preclude an institution having designated copyright experts, or offering copyright education. Three of the institutions with such an agreement provide copyright education, and all five maintain copyright websites. In the follow-up survey, one respondent indicated that their institution plans to opt out of their collective licensing agreement; another institution intends to revisit their agreement regularly to reconsider its value.

\section{Copyright Education}

Five respondents (17.9\%) exited the survey at a branch point asking whether they provide any copyright education or training, after indicating that they do not. Providing copyright education is a mandated or otherwise explicit purpose of the copyright office or position for $81.8 \%$ of the remaining respondents. Most copyright offices $(81.3 \%)$ are mandated to offer education, while fewer than half (41.7\%) of copyright positions are so mandated.

\footnotetext{
${ }^{4}$ This question allowed free-text answers, so answers included estimations such as "7 or 8 years" or "at least 10 years." Where respondents indicated a range, the higher number was used. Where respondents indicated "at least," the number indicated was used. This affects the accuracy of calculations, but gives a general idea of the age of these offices or positions.

${ }^{5}$ Respondents were asked how many staff their copyright office employs, or how many staff have copyright-related duties. They were asked to include both professional and administrative staff if applicable.
} 
A number of factors could explain this discrepancy. A single librarian given responsibility for overseeing copyright may also have other areas of responsibility, such as scholarly communications, limiting the amount of time they can spend on developing and delivering copyright education. Newer positions may still be in the process of defining their role with regard to providing copyright education, or may have plans to develop educational programs in the future once copyright tools and resources have been established. One respondent in the follow-up survey, for example, noted that they "have been in this position for a little over a year, and have focused more on improving the university's copyright compliance program than [they] have on copyright education," though they do value education and plan to develop such programs.

Not many institutions require instructors (13.6\%), staff (13.6\%), or students $(4.5 \%)$ to undertake copyright training or education. Despite this and the disparity between offices and positions in being required to offer education, all responding institutions (100.0\%) provide copyright education for instructors, while $90.9 \%$ provide it for staff and $72.7 \%$ for students. Two respondents (9.1\%) indicated providing copyright education for other audiences, including researchers, authors, and online course developers. Most respondents provide in-person workshops, and more than half offer drop-in sessions (see Table 3). Fewer respondents are using online methods such as webinars or interactive tutorials to educate their patrons, though two additional respondents indicated that online tutorials are under development. Other types of education being offered include direct response to emailed questions, one-on-one sessions with faculty or administration, and educational material provided to new faculty.

\begin{tabular}{l|l|}
\hline Table 3 \\
$\begin{array}{l}\text { Do you provide the following types of education? (Select } \\
\text { all that apply.) ( } \mathrm{n}=22 \text { ) }\end{array}$ \\
$\begin{array}{l}\text { Workshops (in person; scheduled by } \\
\text { request from an individual or } \\
\text { department) }\end{array}$ & 19 \\
\hline $\begin{array}{l}\text { Workshops (in person; scheduled by } \\
\text { the copyright office/position) }\end{array}$ & 18 \\
\hline Drop-in sessions & 13 \\
\hline $\begin{array}{l}\text { Workshops (online, e.g., webinars or } \\
\text { recorded presentations) }\end{array}$ & 6 \\
\hline Interactive tutorials online & 3 \\
\hline Other & 7 \\
\hline
\end{tabular}

Seven respondents' comments about the types of education they feel have been most useful to instructors emphasize in-person methods such as one-on-one consultations or departmental meetings. One respondent feels that "in-person is more effective because instructors come with their own questions based on how they use copyrighted material." This echoes Horava's (2010) argument that copyright is such a complex subject that it "requires personalized attention" (p. 22). However, while in-person education is valuable when possible, considering the independent nature of faculty work and the possibility of 
teaching remotely, the relative lack of online opportunities likely limits the ability of some instructors to access educational opportunities.

\begin{tabular}{|l|l|}
\hline \multicolumn{2}{|l|}{ Table 4} \\
$\begin{array}{l}\text { What topics do your educational opportunities cover? } \\
\text { (Select all that apply.) ( } \mathrm{n}=22)\end{array}$ \\
\hline Copyright basics & 22 \\
\hline $\begin{array}{l}\text { Fair dealing and/or other Copyright Act } \\
\text { provisions }\end{array}$ & 21 \\
\hline $\begin{array}{l}\text { Teaching with copyright-protected } \\
\text { works }\end{array}$ & 20 \\
\hline $\begin{array}{l}\text { Finding copyright-free or openly } \\
\text { licensed sources }\end{array}$ & 16 \\
\hline $\begin{array}{l}\text { Theses (i.e., inclusion of copyright- } \\
\text { protected works) }\end{array}$ & 15 \\
\hline Author rights/publishing & 14 \\
\hline Other & 6 \\
\hline
\end{tabular}

Relatively high numbers of responses in all of the supplied categories of topics indicate that many Canadian institutions are giving their patrons a similar grounding in copyright information (see Table 4). Other topics being covered by respondents include copyright in the learning management system (LMS), subject-specific topics such as "art copyright for fine arts," "using copyright protected works in other functions of the university, such as marketing," and presenting at conferences.

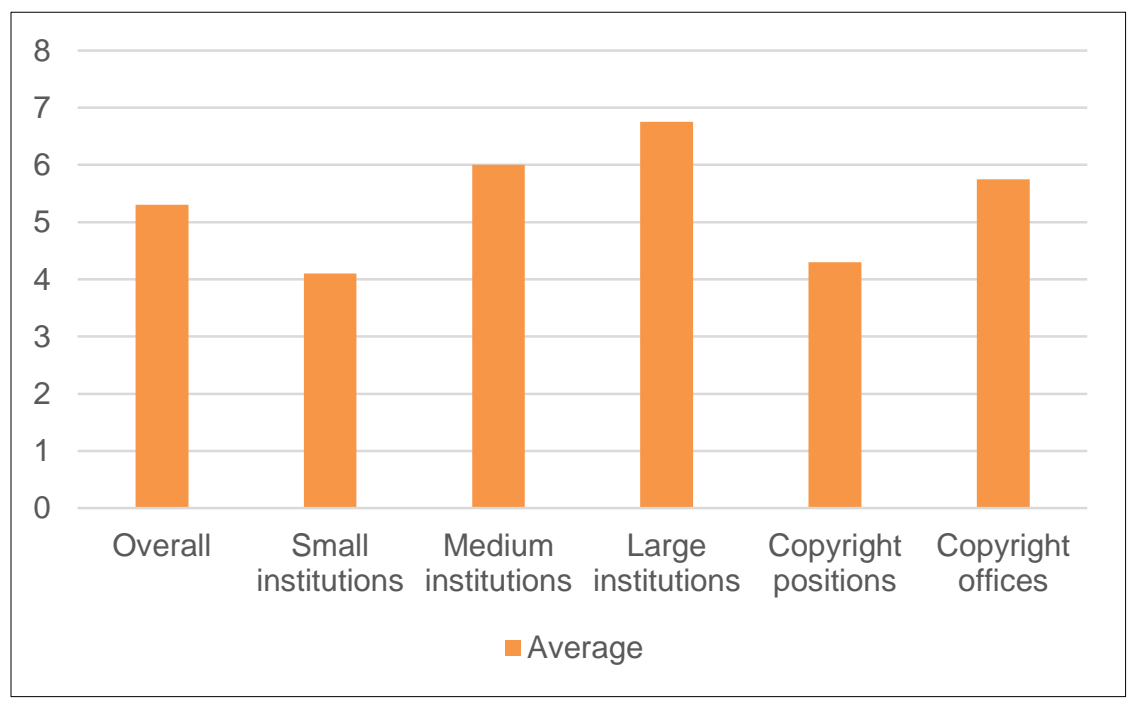

Figure 3. Average number of topics, by institution size and positions vs. offices.

The average number of different topics covered by respondents' educational opportunities, including both supplied options and other topics submitted by respondents, is 5.3. As might be expected, small institutions offer fewer topics than 
medium and large institutions, and copyright offices offer more variety than individual positions (see Figure 3). Thirteen respondents offered additional comments about the topics they find to be most useful to instructors. Seven of these find teaching with copyright-protected works to be the most valuable topic. Five others find fair dealing and/or other Copyright Act provisions to be the most valuable. Open resources, author rights, changes to the Copyright Act, and finding and using library-licensed sources were also mentioned by one respondent each.

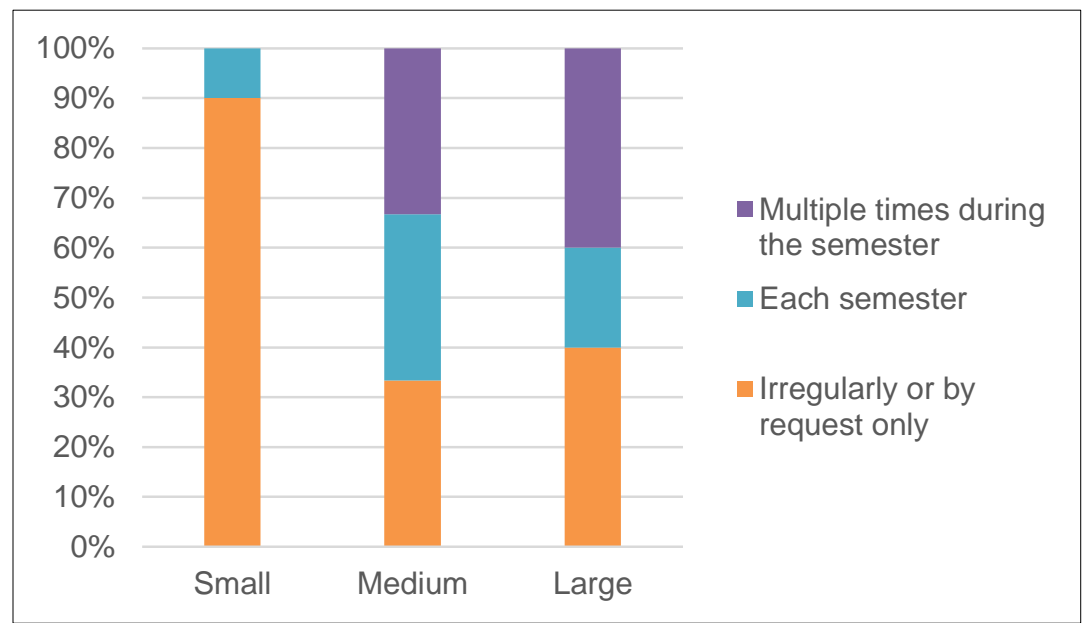

Figure 4. How often do you typically provide scheduled in-person educational opportunities (e.g., workshops, drop-in sessions) to instructors? $(n=22)$.

Nearly half of all respondents (45.5\%), and nearly all small institutions $(90.0 \%)$, only offer in-person education irregularly or by request (see Figure 4). Thirty percent of respondents found that attendance at educational opportunities had fluctuated over time with no clear trend. One-quarter (25.0\%) found that it had decreased and $15.0 \%$ found that it had increased. This lack of common experience may speak to the fluid and constantly-changing character of a given institution's body of instructors, or to difficulties in reaching all instructors with advertising and information about copyright educational opportunities. Five respondents (23.8\%) have stopped offering certain topics or types of education due to lack of interest or attendance. Four of these provided comments: two who have stopped offering drop-in sessions (one of whom had also started only offering workshops by request); one who reduced scheduled workshops in favour of drop-in sessions; and one who had "cut back copyright background/rationale" as a topic in favour of more about copyright basics and educational use of copyright-protected materials.

Many respondents in both surveys commented on their attempts to educate instructors more directly. One respondent noted that their institution is moving away from "more formal training" to instead work directly with individuals such as department secretaries because they are often the first point of contact for faculty with questions; another respondent echoed that they are also working with "administrators from most teaching units individually." Two respondents indicated that they are making efforts to provide copyright information to instructors via departmental meetings and deans' meetings. 


\section{Assessment of Educational Opportunities}

Six respondents (30.0\%) survey workshop attendees in order to gauge the effectiveness of educational opportunities. Four of these survey attendees for feedback specific to the workshop or webinar, including one who also uses a survey at the beginning of workshops for before-and-after comparison. One respondent indicated that workshop feedback was solicited in a student survey about library effectiveness.

Two respondents (10.0\%) survey instructors generally, to assess the level of copyright knowledge at the institution. One of these surveys instructors prior to workshops, and the other administers a survey each semester regarding the use of copyright-protected works in courses.

No respondents indicated using surveys or other assessment tools for any other purpose. The remaining $60.0 \%$ do not use and have not used assessment tools. One respondent indicated that "adding an assessment tool would be a great boon for our presentations," but lack of time and resources has not yet permitted the development of one. Considering the number of general comments about lack of time and staffing in this study and others (see for example Julien et al., 2013), this may also be an impediment to institutions wanting to develop assessment procedures. Another respondent noted that they do ask information session attendees for feedback verbally, but not in a formal or written evaluation.

While it is generally accepted that assessment is a positive and important undertaking in libraries (Fraser, McClure, \& Leahy, 2002; Stoffle \& Phipps, 2003; Lakos \& Phipps, 2004), these and other studies have also found numerous challenges to assessment. Sobel and Sugimoto (2012) found that a majority of respondents in their study "learned how to perform assessments on their own," while only three respondents learned on the job (p. 198; see also Lakos \& Phipps, 2004, p. 351). Sobel and Sugimoto's (2012) study suggested that "many libraries are not creating strong internal cultures of assessment and are leaving it to the internal motivations of individual librarians" (p. 197). In addition to the lack of time discussed above, these studies may provide other insights into the low rate of assessment among respondents.

Six respondents provided comments about changes they had made to educational opportunities based on assessment results. Three of these had added more examples, including examples of reuse or modification of works in theses, citation requirements, and finding sources online; one indicated that such examples and illustrations were added "to enliven the session." One respondent had increased the length of the workshop and added more activities for attendees. A respondent who indicated that participants were surveyed before workshops commented that "session content is directly informed by the survey results." 


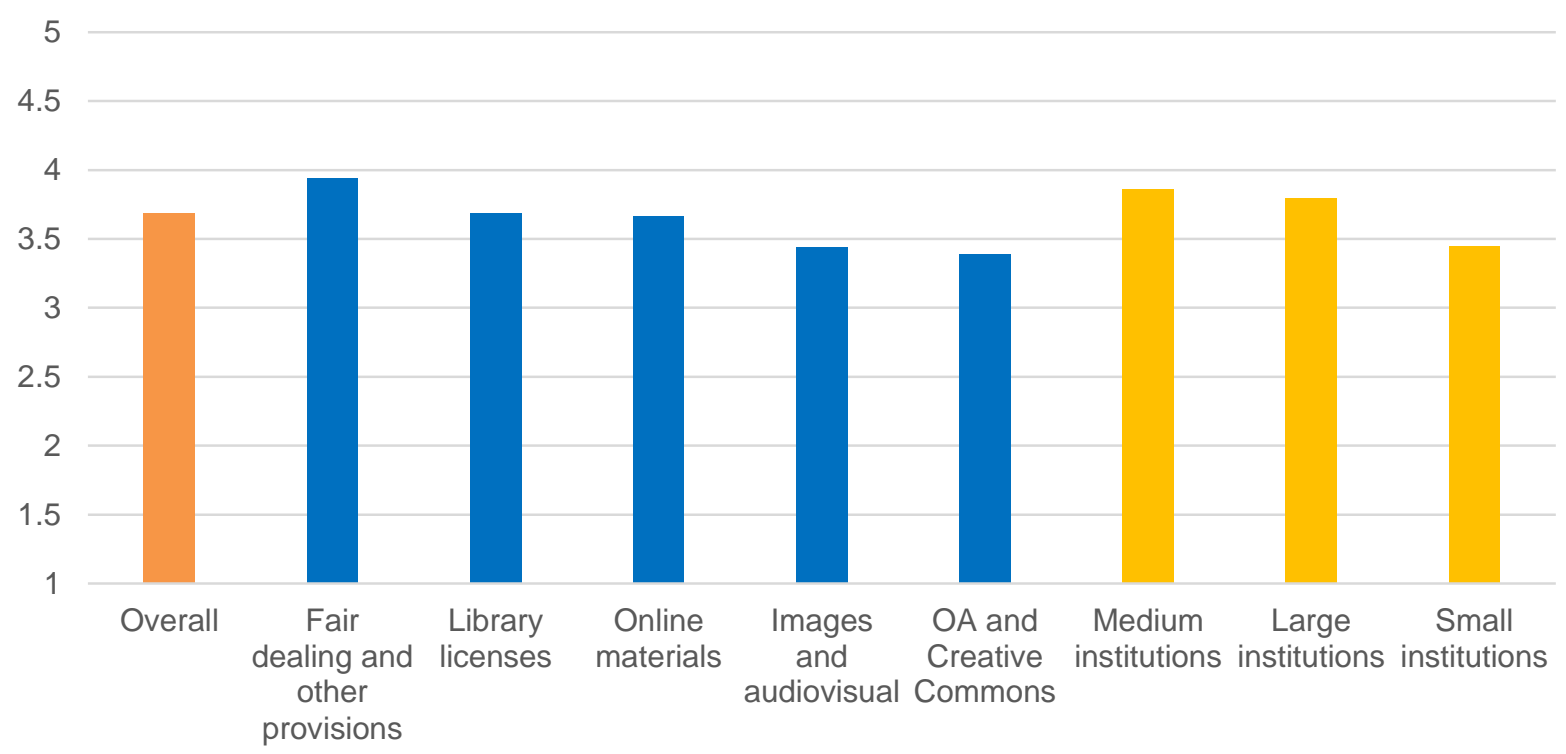

Figure 5. Mean ratings of perceived effectiveness, by topic and institution size $(n=20)$.

With regard to the perceived effectiveness of their educational programs, respondents were asked how confident they are, on a scale of one to five where five is "very confident," that after attending their educational opportunities, instructors are familiar with and comfortable applying certain subjects in their work (see Figure 5).

Respondents have the highest confidence in their coverage of fair dealing and other Copyright Act provisions. Small institutions on average rated their confidence in their educational programs slightly lower than medium and large institutions did. In only one subject, license terms for library materials, did large institutions rate their confidence level lower than small institutions (and then only very slightly, with a mean of 3.50 versus 3.57). The widest discrepancy occurred on the topic of open access (OA) and Creative Commons licensed material, where small institutions rated their confidence level at a mean of 3.11, medium institutions at 3.67, and large institutions at 4.00 . This was also the lowest-rated topic overall.

Those responding institutions who indicated that they do assessment of some kind rated their level of confidence in their educational opportunities only slightly higher than those who do no assessment (a mean of 3.75 versus 3.68 ). In the follow-up survey, respondents who do no assessment indicated that they were comfortable relying on evidence such as informal feedback, the questions raised in workshops and in communication with instructors, and the selection and use of works seen during copyright reviews of course materials. One respondent had noticed that "the questions received by the Copyright Office... tend to be a little bit more complex" than in the past, indicating that instructors are more familiar with copyright basics. Similarly, another receives "far fewer questions about the basics now and mostly [deals] with unusual or particularly complicated scenarios." 


\section{Advertising and Communications}

\begin{tabular}{|l|l|}
\hline \multicolumn{2}{|l|}{ Table 5} \\
$\begin{array}{l}\text { How are your educational opportunities usually advertised? } \\
\text { (Select all that apply.) ( } \mathrm{n}=20)\end{array}$ \\
\hline $\begin{array}{l}\text { Email to target audience (from copyright } \\
\text { office/position or partner department) }\end{array}$ & 16 \\
\hline Library website & 13 \\
\hline Copyright webpage/site & 11 \\
\hline $\begin{array}{l}\text { Email to target audience (from a higher level of } \\
\text { administration, e.g., library, legal, vice president's } \\
\text { office) }\end{array}$ & 10 \\
\hline Library or institution-wide workshop calendar & 5 \\
\hline $\begin{array}{l}\text { Newsletter (from the copyright office or another } \\
\text { department) }\end{array}$ & 5 \\
\hline Social media & 5 \\
\hline Posters on campus & 2 \\
\hline Other & 2 \\
\hline
\end{tabular}

Most responding institutions use email to advertise educational opportunities. Many also advertise via the library's website and a copyright webpage or site (see Table 5). Half $(50.0 \%)$ of the 16 respondents providing comments feel that email is the most successful mode of communication. A number of others (18.8\%) find council, department, and committee meetings to be most successful. Other successful modes of communication include word of mouth, one-on-one conversations, information packages for new staff, newsletters, and the copyright website. It is notable that many of the modes of communication felt to be most effective are in-person methods.

The importance of the source of the communication was also emphasized, in comments like "if it comes from the Provost's office, faculty pay more attention" and "attendance at info sessions is best when the request... comes from the unit itself." This was echoed by a number of respondents in the follow-up survey, one of whom feels that "librarybased educational outreach on copyright will likely always be limited in its reach unless there is ongoing visible support from the highest levels of academic administration."

Many respondents to the follow-up survey do not feel that all instructors at their institution are made adequately aware of educational opportunities. Explanations for this concern include the increasing number of part-time or sessional instructors and difficulty in reaching them through "the usual institutional communication channels we try to leverage (e.g., newsletters, communication from liaison librarians, etc.)," instructors' workloads and schedules, and hiring of instructors "at the last minute, after some communication [of copyright information] has already happened." One respondent feels that "it is almost impossible to reach out to [part-time instructors] because they are basically only on campus to teach their class." Others noted that any method of communication will only reach those who want to be reached: "I think it's easy for 
instructors to find educational opportunities if they look for them;" "I think we're reaching pretty much everyone that wants to be reached." One respondent in the first survey commented that "the university community is likely tired of hearing about copyright [and] instructors who attended a session a couple years ago THINK they know the rules, even though the rules have changed." Given this, any changes resulting from the Copyright Act review beginning in 2017 could provide an opportunity and a context for bringing copyright back to the attention of university communities.

\section{Discussion}

\section{Strategic Education Planning}

Many copyright offices and librarians have found that voluntary workshops, drop-in sessions, or other general types of education are incapable of reaching a broad number of faculty. They are instead finding ways to meet faculty in their departments by attending meetings or by educating administrative figures within the departments whom faculty often approach first with teaching issues and questions. One respondent explained that "since we are getting in at that [departmental] level, instructors are there (either in person, or they'll get mention of our presentation and the slides in their meeting minutes)."

Some also find that having authority figures such as deans or provosts advertise on their behalf lends more weight to copyright messaging: "While faculty don't generally consider copyright unimportant or irrelevant, they tend to prioritize it more when senior university administrators are seen to be prioritizing it;" this reinforces Albitz's (2013) findings. These responses indicate a move toward more strategic education planning, and a more comprehensive approach to communication in general by copyright administrators.

While some of these approaches may help to reach the part-time and sessional instructors who are the key audience copyright administrators feel are being missed, as noted below, more investigation could be made into finding the best ways of reaching these instructors in particular.

\section{Assessment and Documentation}

One-third of the librarians surveyed by Julien et al. (2013) did no evaluation of their information literacy instruction (p. 86); twice as many respondents in this study (60.0\%) do no assessment of their copyright instruction or of the general copyright knowledge levels at their institutions. Yet most respondents feel fairly confident that their educational opportunities for instructors are effective. They are comfortable basing this conclusion on experience, contact with and questions from faculty, and anecdotal evidence. However, as Julien et al. (2013) concluded, "in the absence of articulated instructional objectives and formal evaluation and assessment measures, confidence in instructional outcomes is on rather shaky ground" (p. 100). One respondent acknowledged that due to relying on these informal and subjective measures, they are 
"not sure whether [the] guidelines and copyright law just 'make sense' [to instructors]... or whether it's attributable to [the] copyright office."

The lack of formal evaluation of copyright education is not just a question of making educational programs more interesting or attractive to attendees. Combined with evidence that less than half of institutions audit content uploaded by instructors to their learning management systems (Yolkowski, 2016, n.p.), this suggests a possible lack of comprehensive evidence-based oversight by those responsible for copyright at higher education institutions. While there is a place for "the experience and culture of the librarians and staff" in evidence-based library practice, it should be combined with research and evidence gathering (Bayley \& McKibbon, 2006, p. 320).

As copyright administrators across Canada await the outcome of the ongoing Access Copyright lawsuit against York University (Shen, 2016) and anticipate the possibility of Copibec continuing its lawsuit against Université de Laval (Copibec, 2016), the ability to demonstrate the efficacy of a copyright office or position's policies and practices should be considered. Documentation of the goals and outcomes of educational programs, and the guidance that copyright offices or positions provide regarding the use of copyrightprotected materials by instructors, are important elements of this responsibility.

\section{Online Education and Resources}

Despite comments noting the importance of having copyright information available on a website, few copyright administrators offer online training in the form of webinars $(27.3 \%)$ or interactive tutorials (13.6\%). Most respondents in the follow-up survey see the website as having a different but complementary purpose to the in-person educational opportunities, typified by responses like "there is certainly some overlap between the two, but the website aims at being succinct (like a ready reference source) where in-person sessions aim at being responsive and specific to the individual faculty member."

One respondent also noted an outward-facing purpose of the copyright website: "[it] also serves as proof that we do take protecting copyright seriously, should there be any questions about this from outside groups." This is interesting in light of the lack of assessment discussed above, which arguably would be a more powerful defense of an institution's efforts to ensure that all parties on campus are respecting copyright.

Online educational opportunities could provide better access to part-time and sessional instructors, as well as those who teach from a distance, and should likely be considered as copyright administrators investigate ways to reach this demographic, which is noted by many respondents as being absent from "the usual institutional communication channels." 


\section{Limitations and Areas for Further Study}

The primary limitation on this study is the small sample size. A number of respondents exited the survey early at either of two built-in branch points. These exit options were included to narrow down the pool of respondents to those directly engaged in copyright education and communication, but these factors in addition to the small initial sample size made the number of respondents for each question relatively small. Additionally, all questions were optional, though most respondents who did not exit early did answer most questions.

This survey addressed only the point of view of copyright administrators, rather than the instructors who are the target of the copyright education at subject. This leads to a potential topic for further study: to expand on Di Valentino's (2015) study by surveying faculty with additional questions about methods of copyright education and modes of communication they find most effective. This would be valuable for informing the more targeted and strategic approach to copyright education that a number of institutions are developing. Further study of instructors of all ranks could also address the question, touched on by Di Valentino $(2015$, p. 9$)$ and supported by comments in this study, of whether instructors' status (e.g., part-time vs. full-time, sessional vs. continuing) affects the ability to reach them with copyright and other information.

This study did not investigate institutional preferences for copyright education (e.g., providing guidelines for instructors to interpret as they prepare teaching materials) versus enforcement (e.g., vetting or overseeing instructors' use of copyright-protected materials). This, along with an investigation of whether and how institutions are using the Universities Canada (formerly Association of Universities and Colleges Canada (AUCC)) fair dealing policy (Universities Canada, 2012), or otherwise interpreting fair dealing, would also be a valuable subject for future study.

Finally, depending on the outcomes of both the Access Copyright/York University lawsuit and the 2017 Copyright Act review, any resulting changes to institutional copyright policies and practices could provide an opportunity to follow and assess the development and implementation of new educational opportunities, communication plans, and assessment practices by copyright administrators.

\section{Conclusion}

Instructors at Canadian universities operate autonomously when it comes to preparing their courses and teaching materials. This autonomy, as well as the variety of faculty and non-faculty instructor positions and ranks and the number of communication channels available, makes it difficult to reach this important body of patrons. This is why copyright offices' and copyright librarians' role as educators is fundamental to their purpose. Copyright education programs continue to evolve as copyright administrators respond to instructors' needs. 
When it comes to educating instructors about copyright, without mandatory training a strategic approach may be required in order to reach more members of the academic community. It may be most effective to meet faculty face to face and on their terms by presenting at department or committee meetings. Having a provost, dean, or other higher administrator be the voice of messages about training opportunities or copyright in general can also lend authority and raise the profile of the institution's copyright resources.

With further study and sharing of approaches—both successes and failures—copyright administrators across Canada can develop comprehensive and effective approaches to educating instructors about their copyright rights and responsibilities.

\section{References}

Albitz, R.S. (2013). Copyright information management and the university library: Staffing, organizational placement and authority. The Journal of Academic Librarianship, 39(5), 429-435.

Association of Research Libraries (ARL). (n.d.). Know your copy rights: Using copyrighted works in academic settings.

Bay, M.T. (2001). Libraries and the need to educate users about copyright and fair use. Library Hi Tech News, 18(5), n.p.

Bayley, L., \& McKibbon, A. (2006). Evidence-based librarianship: A personal perspective from the medical/nursing realm. Library Hi Tech, 24(3), 317-323.

Bishop, J. (2011). Copyright across the cohort: A qualitative evaluation of the dissemination of intellectual property information on ARL websites. Library Philosophy and Practice (e-journal). Paper 552.

Canadian Association of Research Libraries (CARL). (n.d.). Some key copyright concepts for librarians, academics, students and researchers.

CCH Canadian Ltd. v Law Society of Upper Canada, 2004 SCC 13, [2004] 1 SCR 339.

Charbonneau, D.H., \& Priehs, M. (2014). Copyright awareness, partnerships, and training issues in academic libraries. The Journal of Academic Librarianship, 40(3-4), 228-233.

Copibec. (2016). Copibec: Authors and publishers will appeal the court's decision denying their class action authorization against Laval University.

Cox, A.M., \& Corrall, S. (2013). Evolving academic library specialties. Journal of the American Society for Information Science and Technology, 64(8), 1526-1542. 
Di Valentino, L. (2015). Awareness and perception of copyright among teaching faculty at Canadian universities. Partnership: The Canadian Journal of Library and Information Practice and Research, 10(2), 1-16.

Duncan, J., Clement, S.K., \& Rozum, B. (2013). Teaching our faculty: Developing copyright and scholarly communication outreach programs. In S. Davis-Kahl and M.K. Hensley (Eds.), Common ground at the nexus of information literacy and scholarly communication (pp. 269-285). Chicago: Association of College and Research Libraries.

Fraser, B.T., McClure, C.R., \& Leahy, E.H. (2002). Toward a framework for assessing library and institutional outcomes. portal: Libraries and the Academy, 2(4), 505528.

Geist, M. (2013). Introduction. In M. Geist (Ed.), The copyright pentalogy: How the Supreme Court of Canada shook the foundations of Canadian copyright law (pp. iii-xii). Ottawa, ON: University of Ottawa Press. Licensed under CC BY-NC-SA 3.0.

Graham, R., \& Winter, C. (2016). Copyright practices and approaches at Canadian universities: Report of a national survey. Paper presented at ABC Copyright Conference, Halifax, NS.

Graveline, J.D. (2011). Launching a successful copyright education program. College \& Undergraduate Libraries, 18(1), 92-96.

Horava, T. (2010). Copyright communication in Canadian academic libraries: A national survey. Canadian Journal of Information and Library Science 34(1), 1-38.

Julien, H., \& Pecoskie, J.L. (2009). Librarians' experiences of the teaching role: Grounded in campus relationships. Library \& Information Sciences Research 31(3), 149-154.

Julien, H., Tan, M., \& Merillat, S. (2013). Instruction for information literacy in Canadian academic libraries: A longitudinal analysis of aims, methods, and success. Canadian Journal of Information and Library Science, 37(2), 81-102.

Katz, A. (2013, May 23). To opt out or not to opt out?

Kawooya, D., Veverka, A., \& Lipinski, T. (2015). The copyright librarian: A study of advertising trends for the period 2006-2013. The Journal of Academic Librarianship 41(3), 341-349.

Lakos, A., \& Phipps, S. (2004). Creating a culture of assessment: A catalyst for organizational change. portal: Libraries and the Academy, 4(3), 345-361. 
MacPherson, C. (2012). $U$ of $S$ rejects copyright agreement. University of Saskatchewan News, n.p.

Patterson, E. (2016). The Canadian university copyright specialist: A cross-Canada selfie. Partnership: The Canadian Journal of Library and Information Practice and Research, 11(2), 1-9.

Quartey, S. (2007). Developing a campus copyright education program. Journal of Interlibrary Loan, Document Delivery \& Electronic Reserve, 18(1), 93-100.

Renner, J.R. (2005). Knowledge level of postsecondary educators regarding copyright and copyright-related issues. In Colleges, code, and copyright: The impact of digital networks and technological controls on copyright and dissemination of information in higher education (pp. 90-115). Chicago: Association of College \& Research Libraries.

Schmidt, L., \& English, M. (2015). Copyright instruction in LIS programs: Report of a survey of standards in the U.S.A. The Journal of Academic Librarianship 41(6), 736-743.

Shen, A. (2016). Copyright back in the spotlight with several impending decisions. University Affairs, n.p.

Sims, N. (2011). Lies, damned lies, and copyright (mis)information: Empowering faculty by addressing key points of confusion. In ACRL 2011 (pp. 282-296). Chicago: Association of College \& Research Libraries.

Sobel, K., \& Sugimoto, C.R. (2012). Assessment of learning during library instruction: Practices, prevalence, and preparation. The Journal of Academic Librarianship, 38(4), 191-204.

Stoffle, C., \& Phipps, S. (2003). Meaningful measures for libraries. Library Issues: Briefings for Faculty and Administrators, 23(4), n.p.

Universities Canada. (2012). Fair dealing policy for universities [Press release].

Universities Canada. (2015). 2015 full-time and part-time fall enrolment at Canadian universities.

University of British Columbia. (2011). Broadcast e-mail: Copyright and fair dealing guidelines, August 8, 2011.

University of Northern British Columbia. (2011). UNBC and Access Copyright (AC) Interim Post-Secondary Educational Institutions Tariff, 2011-2013 (the "Interim $\underline{\text { Tariff"). }}$ 
Partnership: The Canadian Journal of Library and Information Practice and Research, vol. 11, no. 2 (2016)

University of Toronto Libraries. (2015). Open Robarts: U of T Libraries organizes alternate reality game.

Yolkowski, J. (2016). Copyright best practices for learning management systems. Paper presented at $\mathrm{ABC}$ Copyright Conference, Halifax, NS. 


\section{Appendix A: Copyright Education for Instructors at Canadian Post- Secondary Institutions survey instrument}

\section{General information}

Definitions

"Department" includes offices, schools, and any similar identifiable areas within an institution.

"Instructors" includes faculty and non-faculty instructors.

Name of institution

All responses will be aggregated and/or anonymized for use in publication.

[free text]

Does your institution have an office or position dedicated to copyright administration?

a) Yes, we have a dedicated copyright office or equivalent, either independent or within a department (e.g., library, legal)

b) We don't have a dedicated copyright office, but we do have one or more position(s) within a department that are expressly responsible for copyright (possibly alongside other responsibilities, e.g., copyright specialist, scholarly communications librarian)

c) No, there is no centralized responsibility for copyright administration. Copyrightrelated issues are handled ad hoc in different departments (e.g., library, research office, bookstore)

d) I don't know

If you selected "No..." or "I don't know" above but you have any responsibilities related to copyright education, please continue through the survey, answering any questions you are able to address.

If you selected "No..." or "I don't know" above and are unable to address copyright education at your institution, please forward the survey link to an appropriate individual, or click below to go to the end of the survey. Thank you for your time.

Click here to go to the end of the survey

\section{Your copyright office or position}

The following questions ask about the role of your office (if you indicated that your institution has a copyright office or equivalent) or your position (if you indicated that one or more positions at your institution include copyright-related duties).

How many years has your copyright office/position been in operation? [free text] 
Is your copyright office/position organizationally situated in:
a) Library
b) Legal office
c) University administration
d) Other, please specify...

How many staff does your copyright office employ, OR how many staff at your institution have copyright-related duties (please include professional and administrative staff if applicable)?

[free text]

Does your institution currently have an agreement with Access Copyright or Copibec?
a) Yes
b) No
c) I don't know

Does your institution have a website or webpage containing copyright information for instructors, students, and/or staff?
a) Yes, please indicate the URL: [free text]
b) No

If yes, is your office/position primarily responsible for maintaining the site/page and its content?
a) Yes
b) No

Do you or does your office provide copyright education or training (e.g. workshops, online tutorials, drop-in sessions)?

Selecting "No" below will take you to the end of the survey. Thank you for your time.
a) Yes
b) No (we only answer questions directly and/or provide "self-serve" material such as FAQs or subject guides)

\section{Copyright education at your institution}

Is providing copyright education a mandated or otherwise explicit purpose of your office or position?
a) Yes
b) No

Is any copyright education or training required by your institution for... Instructors?
a) Yes
b) No
c) I don't know 
Students?
a) Yes
b) No
c) I don't know

Staff?
a) Yes
b) No
c) I don't know

Do you provide copyright education for the following audiences? (Select all that apply)
a) Instructors
b) Students
c) Staff
d) Other, please specify... [free text]

Do you provide the following types of education? (Select all that apply)
a) Workshops (in person; scheduled by the copyright office/position)
b) Workshops (in person; scheduled by request from an individual or department)
c) Workshops (online, e.g. webinars or recorded presentations)
d) Interactive tutorials online
e) Drop-in sessions
f) Other, please specify... [free text]

What topics do your educational opportunities cover? (Select all that apply)
a) Copyright basics
b) Teaching with copyright protected works
c) Finding copyright-free or openly licensed sources
d) Fair dealing and/or other Copyright Act provisions
e) Theses (i.e. inclusion of copyright protected works)
f) Author rights/publishing
g) Other, please specify... [free text]

What types of education and/or topics do you feel have been most useful to instructors at your institution, and why?

[free text]

Does your office/position provide educational opportunities alone, and/or in partnership with another department (e.g. thesis office, teaching and learning department)? (Select all that apply)
a) Alone
b) With other departments, please specify... [free text] 


\section{Your copyright educational opportunities}

How often do you typically provide scheduled in-person educational opportunities (e.g. workshops, drop-in sessions) to instructors?
a) Annually
b) Each semester/term
c) Multiple times throughout the semester/term
d) Irregularly or by request only
e) Other, please specify... [free text]
f) Scheduled in-person education is not provided for instructors

Over time, has attendance (if in-person) or views (if online) of your educational opportunities for instructors generally
a) Increased
b) Decreased
c) Stayed the same
d) Fluctuated with no clear trend
e) Unsure

Are there any specific topics or types of education you have stopped offering due to lack of interest or attendance?
a) Yes
b) No

If yes, please specify topics or types of education cancelled:

[free text]

\section{Assessment of copyright education}

Do you use / have you used surveys or other assessment tools? (Select all that apply)

a) Yes, with attendees, to gauge the effectiveness of our educational opportunities (please describe) [free text]

b) Yes, with instructors, staff, and/or students generally, to assess the level of copyright knowledge at our institution (please describe) [free text]

c) Yes, for another purpose (please explain) [free text]

d) No, we don't use / haven't used assessment tools

If you selected any "Yes" option above, have you changed any of your educational opportunities (e.g. content or format) based on the results? If so, what kinds of changes have you made?

[free text] 
Effectiveness of your educational opportunities for instructors How confident are you that after attending or viewing your educational opportunities, instructors are familiar with the following concepts and comfortable applying them in their work?

1 = Not at all confident; 5 = Very confident (options included "Unsure" and "Our educational opportunities don't cover this")

a) Fair dealing and other Copyright Act provisions

b) Terms of licenses for journals and other materials from the institution's library

c) Open Access and Creative Commons material

d) Using images and audiovisual material compliantly

e) Using material found online compliantly

Would you like to elaborate on any of your answers to this question?

[free text]

\section{Advertising educational opportunities}

How are your educational opportunities usually advertised? (Select all that apply)

a) Copyright webpage/site

b) Library website

c) Email to target audience (from copyright office/position or partner department)

d) Email to target audience (from a higher level of administration, e.g. legal, vice president's office)

e) Posters on campus

f) Library or institution-wide workshop calendar

g) Newsletter (from the copyright office or another department)

h) Social media

i) Other, please specify... [free text]

What do you feel has been the most successful mode of communication for advertising copyright workshops, other training, or informational resources at your institution, and why? [free text]

\section{Additional comments and follow-up}

Would you like to provide any additional comments on the subject of copyright education for instructors at your institution?

[free text] 
May I follow up with you by email or telephone with additional questions if necessary? All responses will be confidential, and will be aggregated and/or anonymized for any use in publication.

a) Yes (please indicate name, preferred method of contact, and contact information) [free text]

b) No

Thank you for participating. 


\section{Appendix B: Follow-up Survey Questions}

The follow-up survey was administered by email and respondents were asked to respond in a Word document, so all questions are open-ended.

Every follow-up respondent was asked the following questions:

- Do you feel all instructors at your institution are made adequately aware of educational opportunities? Please elaborate on why/why not.

- Is the content covered in your in-person workshops duplicated in your copyright website (either directly, e.g. workshop slides posted online, or indirectly, e.g. through FAQs or other formats)? Do you think one source of information (i.e. inperson or online) is more effective than the other, or do they meet different needs in your community? Do you have any further thoughts on in-person compared to online education for faculty?

- Do you have any further thoughts on copyright education for instructors?

Additional questions varied from respondent to respondent, based on their answers or comments in the first survey. Examples include:

- You indicated that you don't use surveys or other assessment tools, either to evaluate your educational opportunities or to assess the general knowledge level at your institution. What information sources informed your ratings of the effectiveness of your educational opportunities?

- You indicated that you provide a wide variety of education formats (workshops in person, scheduled by the copyright office/position; workshops in person scheduled by request; webinars or other online workshops; interactive tutorials online; and drop-in sessions). Do you think one format is more effective than others, or do they meet different needs in your community? Do you have any further thoughts on the format of educational opportunities for faculty?

- You indicated that your office has started presenting to faculty directly at departmental meetings. What made you decide to move in this direction and away from scheduled workshops? Did you or someone else in your copyright office approach departments about addressing copyright at meetings, or did they come to you with this idea?

- You indicated that you often work one-on-one with instructors. Are these meetings arranged in a systematic way in order to review general copyright information, or do instructors approach your office only when they have specific questions? 
- If your institution has considered/is considering opting out of an Access Copyright agreement in the future, have you thought about how that might change your educational opportunities? If so, what changes would you make, if any? 